\title{
The Politics of Education and its Impact on the Human Exploration of Mars
}

\author{
Viktoriya Timashova \\ Doctor of Political Sciences, Associate Professor, \\ National Pedagogical Dragomanov University (Kyiv, Ukraine) \\ E-mail: tavitum@bigmir.net \\ https://orcid.org/0000-0001-5717-9476
}

\section{Hanna Strohanova}

Ph.D. in Pedagogical Sciences, National Pedagogical Dragomanov University

(Kyiv, Ukraine)

E-mail: gannastroganova@gmail.com

https://orcid.org/0000-0003-2900-3152

In the article, the authors examined briefly the relationship between the politics and education in the history of culture. As a result, the authors confirmed the relevance of the politics of education. The possibilities of the politics of education to influence the ontology of the younger generations were examined. In particular, the influence of the politics of education on the development of society through the modernization of the teacher training system and the family policy of the State was examined. The authors focused mainly on clarifying the mechanism of influence of the politics of education in public schools. The authors came to the conclusion that one of the ways the politics of education affect the younger generations is creation of the certain "myth-triggered" and maintenance their relevance by using various sets of brain neuro-programming technologies. The authors examined the formation features, the sequence of actions, and the consequences of the impact of the myths-triggered such as "the need for space exploration" and "human exploration of Mars".

Keywords: politics of education, school politics, space exploration, brain neuro-programming technologies, myth-triggered, human exploration of Mars,

Received: May 15, 2019; accepted: June 12, 2019

Philosophy and Cosmology, Volume 24, 2020: 122-130.

https://doi.org/10.29202/phil-cosm/24/12

(C) Timashova, Viktoriya, 2020

(C) Strohanova, Hanna, 2020 


\section{Introduction}

In 1959, while American schools were barred from politics, Thomas H. Eliot presented a study in which he proved that neglecting public school policies was a mistake. In the article "Toward an Understanding of Public School Politics" Eliot proved that a public school policy was a significant domain of policymaking and political power exertion (Eliot, 1959).

The decades that preceded Eliot's article passed in the United States under the slogan "get politics out of the schools and get the schools out of politics." Until the 1960s, leaders in urban reform and progressive education in the United States worked to prove that a politics of education does not exist. An attempt was made to impose the point of view that politics and education are not compatible in public school education. As Douglas Mitchell and Lisa Romero note, "The persuasive presentation of this ideology of a schooling system free of politics is properly seen as one of the most successful political strategies in this nation's history" (Mitchell \& Romero, 2017). However, Eliot's article drew attention to processes that claimed the opposite. These processes were discordant with the assertion that students should be protected from the influence of politics.

Two decades later, Paulo Freire stated that education was political in nature (Freire, 1993). Freire argued that it was wrong to consider education as a neutral "mechanical method of instruction' (McLaren \& Leonard, 1993). The point of view of the authoritative teacher in the world crossed out essentially the attempts of American officials and "reformers" in the field of education to redraw the history of education.

Division of politics and education is unnaturally by the nature. It manifests distinctly in the history of education. The first extant theory of education that has survived is set forth in Plato's book "The Republic". Plato understood Paideia as shaping of a person's character in accordance with the dominant ideas and ideals in society. Plato did not separate education from politics. On the contrary, Plato's education was the main force of government. In Plato's theory of education, the caste of philosophers who governed the ideal State brought the demos (people) to the Sun or to the image of the Supreme idea by means of the Paideia or the force of education (Griffith, 2000).

The close connection between education and politics, on which ancient Greek Paideia was based, has not been forgotten in the history of culture. Oleg Bazaluk investigated the transition of the basic meanings of Greek Paideia into the education of the middle Ages. Bazaluk proved that the Fathers of the Church had preserved the basic provisions of the theory of education of Antiquity, only they had stated them in the new terms (Bazaluk, 2018). Instead of the image of the Sun as the highest idea, the Church Fathers used the power of education to achieve new political ideals and goals.

During the New Age period in European culture, the connection between politics and education had long been regarded as an obvious phenomenon. Education was considered "as the motor of global capitalism and the production of human capital" (Nordensvard, 2014: 340). Each new generation enriched the meanings of education, the ways and means of its impact on humans. However, the existing connection between education and politics was not disputed in the continental history of culture.

Johan Nordensvard claims that neo-liberal education policies are based on neo-liberal discourse. In fact, the modern and widespread image of education has "the political ideology that enforces market rule on more and more aspects of social life all over the world" (Nordensvard, 2014: 340).

The period of "reforming" of American education, when education was artificially isolated from politics, takes a small amount of time in the history of culture. On the whole, 
the thousand-year history of education is revealed in the image of continuously evolving relations between education and politics. Views on education and politics, as well as views on the relationship between education and politics, have evolved. In modern society, views on education have returned to the traditions of Isocrates. Education is not considered in the philosophical traditions, which were founded by Socrates, Plato, Aristotle and Neoplatonists. Education is seen as a service sector, i.e. in the traditions of Isocrates and the Stoics.

In the modern world, the main service of education is the formation of certain stable stereotypes of attitudes and norms of behavior that correspond to the ideas, ideals and values of society. Education forms the image of a citizen in accordance with certain cultural values, norms of behavior, or the dominant idea in society. Depending on the form of government in the state, education is used by the political system as the nominal or real power (Svyrydenko \& Yatsenko, 2018).

In today's society, politics delegates some of its functions to education. In particular, politics transfers to education the most important technologies of influence on the masses that allows us to assert not only the relevance of politics of education, but also the real impact of politics of education in public school education.

\section{Modern opportunities of politics of education}

In the book "Changing Politics of Education", the authors describe public education's assets and resources, and also prove the fallacy of replacing politics of education with the attributes of the modern so-called "educational reform". Michael Fabricant and Michelle Fine proved that high stakes testing and market mechanisms such as incentives, choice, and competition are only undermine learning and constrict educational opportunity (Fabricant \& Fine, 2015).

Criticizing "educational reform" in the USA, Fabricant and Fine point to one of the reasons for the erroneous attitude to politics of education and underestimation of its capabilities. Politics of education should be considered as schooling in the context of world economic and political ideology and practice, and not in corporate style. And this is just one of the reasons. Fabricant and Fine believe that the rejection of politics of education leads to the rejection of public education and the glorious history that public education has carried out, is carrying out, and will continue to carry out in society. According to Fabricant and Fine, the rejection of politics of education will lead to "a strong increase mightily expanding the inequalities of wealth, darkening the futures of the dispossessed, and cannibalizing what remains of democratic spirit in a corporate society" (Fabricant \& Fine, 2015).

The book by Fabricant and Fine reveals not only the possibilities of politics of education. It calls for action. The authors suggest the concrete steps to organize the influence of politics of education in public school education.

In the American tradition, the possibilities of politics of education are considered mainly in relation to the possibilities of state school institutions. However, taking into account how important the school period is in the formation of the key worldviews of a person, we can argue that politics of education influences key processes of the life of society, such as political modernization of society, features of the development of political institutions and political relations, etc.

For example, politics of education has a direct impact on the modernization of teacher training. Teachers are taught new technologies to influence the formation of unconscious and conscious behavior of younger generations. They learn to communicate effectively, to form appropriate habits, preferences, inclinations, etc. Politics of education turns teachers 
into important actors in strategies for adapting a person to the characteristics of the existing political system (Nesterova, 2017). With the help of teachers and an appropriately selected school curriculum, the current political system forms in the younger generations a political ideology and image of a higher idea. Through the training of teachers, their professional qualities and political convictions, the political system ensures the continuity and necessary modernization of the foundations of society. Politicians and government executives use a wealth of methods and methods of politics of education to form their own strategies in the worldview of the younger generations, which are planned to be implemented in the near future.

Politics of education has a direct impact on family policy of the State. The family policy features are revealed in the article by Denys Svyrydenko and Dariusz Tulowiecki (Svyrydenko \& Tulowiecki, 2018). The family creates an emotional environment in which the worldview of the child is formed. Building and maintaining an adequate family support policy just depend on politics of education. Politics of education forms the attitude towards the family as a social value, and as a feedback, the family provides the evolution of the political system as a macro-social system. Influence on the family eliminates a number of key risks for society and the political system. For example, the problem of low (or high) fertility, which can lead to violence, divorce, migration, and other uncontrolled processes that destabilize civil society and the political system. The family creates favorable (or unfavorable) conditions for involving children in new ideas that the political system plans to implement in the near future. This may be the idea of digitizing society, or, for example, the need for space exploration.

Politics of education has the ability to regulate access to information. Providing the priority of this or that information, its accessibility, quality, visibility, perception, etc., the political system forms an emotional attitude to the ideas that are priority for it. For example, through comics, children's literature, films for children, etc., one can form realism (or vice versa, not realism), artificial intelligence, and space technologies (Soroka \& Kurkova, 2019).

The formation of the realism of the idea of creating artificial intelligence and its use in space technologies in the school period leads to the formation of a sustainable behavior strategy in the adult period. From a childhood dream, an idea passes into a goal and a way of life. The society receives a highly qualified specialist in the field of information and communication technologies, whose direction of self-realization was formed precisely by politics of education.

\section{The mechanism of the influence of politics of education on younger generations: the creation of myth-triggered and their actualization}

Despite the obvious advantages of the book by Michael Fabricant and Michelle Fine, from our point of view, the mechanism of influence of politics of education on the younger generations has a different fundamental basis. This basis is not in the plane of interpersonal communication or communication between social institutions and social groups. This basis is in the plane of influence of politics of education on neurobiological processes and psychology of a person. In fact, this influences on the ontology of man and leads to the formation of stable views and motives of behavior. This influence turns into a key force in the shaping of man even in complex and variable conditions of social influence. It determines the direction and limits of human self-realization. 
We believe that the mechanism of influence of politics of education on the younger generations should be considered as the influence of neuro-programming technologies. In the article "The Importance of the Brain Neuro-Programming Technologies in National and Regional Security Strategies," the authors consider the history and features of the formation of the brain neuro-programming technologies in the history of culture (Fatkhutdinov \& Bazaluk, 2018). According to the authors, the brain neuro-programming technologies originate in the ancient ideas about education. At those times in Ancient Greece, education was considered as a technology for shaping human behavior in accordance with a certain ideal. With each generation, the brain neuro-programming technologies evolved. New opportunities for their application opened up. Neuroscience studies revealed the features of formation of the foundations of the human worldview, thereby improving the brain neuroprogramming technologies and their impact on the brain. As it follows from the study by Vasyl Fatkhutdinov and Oleg Bazaluk, at present the brain neuro-programming technologies have become applied skillfully in the creation and implementation of national and regional security strategies. With their help, it is possible to form attitudes towards national minorities (tolerance or intolerance of views), neighbouring Nations (aggressiveness or peacefulness) and other cultures (tolerance or rejection). The intensive development of the brain neuroprogramming technologies allows politicians to regulate the orientation and opportunities for self-realization of the younger generations.

Svitlana Balinchenko's research reveals one of the mechanisms of influence of brain neuro-programming technologies on the human brain. With the help of Balinchenko's research, we can explain more easily the mechanism of influence of politics of education on the younger generations. Balinchenko had explored two important issues that revealed the role and importance of politics of education in modern society. First, the ability of mass media to create myths and using myths to disrupt communication in society. Second, Balinchenko considered the variety of possible mechanisms for overcoming the myths (Balinchenko, 2019).

Thus, one of the ways of making impact on younger generations by politics of education is creation of certain "myth-triggered" (in Balinchenko's terminology) and maintain their relevance.

\section{The sequence of actions of politics of education when creating the myth-triggered "the need for space exploration"}

Let us consider the sequence of actions of politics of education when creating mythtriggered, which is conventionally called "the need for space exploration". This mythtriggered is formed under the influence of the brain neuro-programming technologies, relevant for children, adolescents and youth periods.

The myth-triggered, called "the need for space exploration", forms in the worldview of the younger generation a whole network of stable stereotypes of views associated, for example, with the beliefs that space exploration:

a) is the only way to save humanity in the terms of expanding Universe;

b) will open access to the resources of space, without which humanity is doomed to self-extinction;

c) will allow to make a new industrial revolution, which will bring humanity to a new qualitative level of development and open access to new material benefits;

d) will open up opportunities for space colonization and provide interaction with extraterrestrial civilizations. 
The political system uses the possibilities of politics of education to actualize the created myth-triggered. It turns it into an ideology of a schooling system. In public school education, a whole range of activities is carried out, which has the following sequence of actions:

1. The brain neuro-programming technology as the priority goal is established in teacher training and retraining courses. Teachers, as the key actors in neuroprogramming, aim to formulate the concrete myth-triggered in schools. Teachers are taught to form a stable understanding of space exploration in schoolchildren of different ages as the only possible way of human self-rescue.

2. Through existing communicative relationships, there is the same effect of politics of education on parents, the second key actors in neuroprogramming. Parents are taught a new myth-triggered. An information matrix is created around the parents, the key idea of which is the idea that the future of the child is possible only in the emerging market of space services. Parents are trained to create conditions in the family that facilitate the emotional perception of the myth-triggered child.

3. Special literature, films, music, and other media that most effectively convey the myth-triggered to the child during school hours are selected. This literature is made to be accessible for the child as much as possible, while information that denies or destroys the myth-triggered is isolated as much as possible.

4. The political system uses the possibilities of mass literature and television to create an information matrix around the child outside the school. The child receives confirmation of the myth-triggered in the usual emotional environment of his family, friends, in the images of heroes and idols close to him.

5. Every minute around the child, during the entire wakefulness of the brain lasting for years and decades, an information matrix has been operating, which has a continuous impact on the emerging brain. It forms the neurobiological basis of the myth-triggered.

6. The older the child becomes, the more effective the incentives that encourage selfrealization of the internal potentials according to the myth-triggered begin to act. At the same time, more serious condemnation meets self-realization, which does not correspond to the created myth-triggered.

As a result of the complex of actions and their all-encompassing nature, which organizes the politics of education, the myth-triggered about space exploration as the only "right" way of evolution of society, moves into a stable system of views. The political system uses the myth-triggered and the possibilities of politics of education to turn the idea of "the need for space exploration" into a way of life. Self-realization of new generations focuses on space exploration. Detail beyond the borders of the planet is seen as the norm.

Thus, space exploration as the myth-triggered, actualized by the politics of education, drives the transformation of all spheres of human civilization: the political system, social institutions, economy, and culture.

In our study, we do not aim to assess the "correctness" or "incorrectness" of the mythstriggered created and operating in modern society, with the help of which politics of education influences the evolution of society. We investigate the features of the influence of politics of education on a person's lifestyle. The creation of the myths-triggered and their actualization, is a proper example of the possibilities of politics of education. The action of the mythstriggered reveals the scale of the influence of politics of education on the spheres of human activity. 


\section{Creation and actualization of "human exploration of Mars" as the myth-triggered}

Let us consider another idea that politics of education forms in the younger generations in our time as the myth-triggered. This is "human exploration of Mars" as a stable system of views that allows us to justify the actions of governments and the huge material resources that are spent on the implementation of this idea.

The first ideas of human exploration of Mars originated in the 50s of the twentieth century. During that period, large companies representing the entertainment industry actively invested it. This is interesting tells Jack Stuster (Stuster, 2019). At that time, the scientific community perceived the idea of human exploration of Mars as a bad idea. Jack Stuster talks about it very interestingly (Stuster, 2019). At that time, scientific communities perceived the idea of human exploration of Mars as mauvais tone (inappropriate practice).

The attitude of scientists to the idea of human exploration of Mars and human settlement in space changed dramatically after the first space flights of the astronauts and especially after the flights and landing of the American astronauts on the Moon (Krichevsky, 2017). The active creation of "human exploration of Mars" as the myth-triggered, caused and supported by the competition between the USA and the USSR, two superpowers of that period, began.

The created myth-triggered was actively implemented in public school education by using the possibilities of politics of education. The result of the impact of politics of education on the younger generations was the fact that by the end of the $20^{\text {th }}$ century - the beginning of the $21^{\text {st }}$ century, "human exploration of Mars" as the myth-triggered, began to determine the way of life of new generations. Governmental and non-governmental organizations, and research teams were created to work on the embodiment of the myth into reality. In practice, the created and updated myth-triggered led to the following results. The NASA Authorization Act of 2005 articulated a new strategy for the nation's space program by specifically stating that "The Administrator shall establish a program to develop a sustained human presence on the Moon, including a robust precursor program, to promote exploration, science, commerce, and United States preeminence in space, and as a stepping-stone to future exploration of Mars and other destinations" (Human exploration of Mars, 2009). Recognizing the need for an updated and unified reference architecture for human exploration of Mars, NASA Headquarters commissioned The Mars Architecture Working Group (MAWG) in January 2007 to develop the Mars Design Reference Architecture 5.0 (DRA 5.0). The Mars Design Reference Architecture (DRA 5.0) describes the systems and operations that would be used for the first three missions to explore the surface of Mars by humans.

NASA created and actively operates The Mars Exploration Program Analysis Group (MEPAG) (https://mepag.jpl.nasa.gov/). At the NASA workshop, which took place in late February 2017, the scientific investigations associated with the human exploration of Mars in the next 35 years were presented. (Niles et al., 2017). At the workshop, a summary of the findings of the Human Science Objectives Science Analysis Group, or HSO-SAG chartered by MEPAG in 2015 to address science objectives and landing site criteria for future human missions to Mars were presented. Currently, NASA's plan to land astronauts on Mars in the mid 2030's would allow for robust human exploration of the surface in the next 35 years. We expect that crews would be able to traverse to sites up to $100 \mathrm{~km}$ away from the original landing site using robust rovers. The main argument for the need for the human exploration of Mars was called A human mission to Mars would present an unprecedented opportunity to investigate the earliest history of the solar system, as well as to investigate scientific 
questions ranging from the nature of the impact history of the solar system to the origins of life (Niles et al., 2017).

Numerous subsequent research studies address various aspects of human exploration of Mars. For example, Ja'Mar A. Watson in his study benchmarks the Mars DRA 5.0 by quantifying its mission utility in satisfying mission objectives derived from human exploration of Mars community consensus. Watson proves that the DRA's mission utility is limited due to a lack of its consideration during design (Watson, 2019). Jack Stuster considers several NASA risks by identifying the work that will be performed during an expedition to Mars and the abilities, skills, and knowledge that will be required of crew members (Stuster, 2019). Professor Mihai G. Netea and his co-authors reviewed a set of safety measures to prevent, diagnose and eventually treat infections with Martian microorganisms (Netea et al., 2019).

Thus, we can state that half a century after its creation, "human exploration of Mars" as the myth-triggered became an everyday way of life. Thanks to the possibilities of politics of education this myth-triggered turned into a reality that in a decade will be embodied in the first settlements on Mars.

\section{Conclusions}

In the article, the authors examined the possibilities of politics of education to influence the evolution of society and its foundations. The authors analyzed one of the ways of this influence: the creation of the myths-triggered, which through the sets of brain neuroprogramming technologies form stable stereotypes of views and human behavior. The authors examined the features of formation, the sequence of actions, and the consequences of the impact of the myths-triggered, such as "the need for space exploration" and "human exploration of Mars". Thanks to the possibilities of politics of education, these myth-triggered have become a reality. Currently, they determine the direction and limits of self-realization of modern society.

\section{[ㅁ] References}

Balinchenko, Svitlana. (2019) Mythologeme-Related Crisis of Identity: Reality and Fictional Markers of Alienation. Future Human Image, Volume 11, 5-13. https://doi. org/10.29202/fhi/11/1

Bazaluk, Oleg. (2018) The Feature Transformations of the Basic Meanings of Greek Paideia in the Educational Theories in the Middle Ages. Schole, Vol. 12.1, 243-258. https:// doi.org/10.21267/AQUILO.2018.12.10428

Eliot, Thomas. (1959) Toward an Understanding of Public School Politics. American Political Science Review. Volume 53, Issue 4, 1032-1051. https://doi.org/10.2307/1952073

Fabricant, Michael, and Michelle Fine. (2015) Changing Politics of Education: Privitization and the Dispossessed Lives Left Behind. Routledge.

Fatkhutdinov, Vasyl H. and Oleg Bazaluk. (2018) The Importance of the Brain NeuroProgramming Technologies in National and Regional Security Strategies. Philosophy and Cosmology, Volume 20, 74-82. https://doi.org/10.29202/phil-cosm/20/6

Freire, Paulo. (1993) Pedagogy of the oppressed. New York: Continuum.

Griffith, Tom. (2000) Plato: The Republic. Cambridge: Cambridge University Press.

Human exploration of Mars, Design Reference Architecture 5.0. (2009) Bret G. Drake, editor. NASA Johnson Space Center, Houston, Texas, July 2009. https://www.nasa. gov/pdf/373665main_NASA-SP-2009-566.pdf 
Krichevsky, Sergey. (2017) Cosmic Humanity: Utopia, Realities, Prospects. Future Human Image. Volume 7, 50-70.

McLaren, Peter, and Peter Leonard. (1993) Paulo Freire: a critical encounter. London: Routledge. http://dx.doi.org/10.4324/9780203420263

Mitchell, Douglas E., and Lisa Romero. (2017) Politics of Education. Oxford Bibliographies. https://doi.org/10.1093/OBO/9780199756810-0129

Nesterova, Marja. (2017) Educational Cognitive Technologies as Human Adaptation Strategies. Future Human Image, Volume 7, 102-112

Netea, Mihai G., Frank L. van de Veerdonk, Marc Strous and Jos W.M. van der Meer. (2019) Infection Risk of a Human Mission to Mars. Journal of Astrobiology and Space Science Reviews, 1, 144-155. http://journalofastrobiology.com/Mars11.html

Niles, P. B., David Beaty, Lindsay Hays, Deborah Bass, Mary Sue Bell, Jake Bleacher, Nathalie A. Cabrol, Pan Conrad, et al. (2017) Scientific Investigations Associated with the Human Exploration of Mars in the Next 35 Years. NASA Planetary Science Vision 2050 Workshop; February 27, 2017 — March 01, 2017; Washington, DC; United States.

Nordensvard, Johan. (2014) The Politics of Education: education from a political and citizenship discourse. Policy Futures in Education, Volume 12, Number 3. https://doi. org/10.2304/pfie.2014.12.3.340

Soroka, Larysa, and Kseniia Kurkova. (2019) Artificial Intelligence and Space Technologies: Legal, Ethical and Technological Issues. Advanced Space Law, Volume 3, 131-139. https://doi.org/10.29202/asl/2019/3/11

Stuster, Jack. (2019) Tasks and Abilities for the Human Exploration of Mars. Space Studies Colloquium. 73. https://commons.und.edu/ss-colloquium/73

Svyrydenko, Denys, and Olena Yatsenko. (2018) Dialectics of Nominal and Real Power in the Ukrainian and World Politics. Ukrainian Policymaker, Volume 2, 33-40. https:// doi.org/10.29202/up/2/5

Svyrydenko, Denys, and Dariusz Tulowiecki. (2018) Family Policy of the State as a Response to Social Security Threats. Future Human Image, Volume 10, 92-102. https://doi. org $/ 10.29202 /$ fhi $/ 10 / 10$

Watson, Ja'Mar A. (2019) Benchmarking the human exploration of Mars Design Reference Architecture. International Journal of Space Science and Engineering, Volume 5, Issue 2. https://doi.org/10.1504/IJSPACESE.2019.097410 